\title{
Performance Characteristics of Megaregion Traffic Networks During Mass Evacuations
}

\author{
Zhao Zhang $^{1}$, Katherine Spansel ${ }^{2}$, Vinayak Dixit ${ }^{3}$ and Brian Wolshon ${ }^{2}$ \\ ${ }^{1}$ Department of Industrial Engineering, Tsinghua University \\ ${ }^{2}$ Gulf Coast Center for Evacuation and Transportation Resiliency \\ Louisiana State University \\ ${ }^{3}$ University of New South Wales \\ zhaozhang1111@gmail.com,kspansel@lsu.edu,v.dixit@unsw.edu.au, \\ brian@rsip.lsu.edu
}

\begin{abstract}
The significant and continuous growth of urbanized areas throughout the world has led to the emergence of the global phenomenon of megaregions. Megaregions often share common historical, cultural, environmental, and topographic/geologic systems as well as close economic ties, facilitated by transportation linkages that connect the movement of people and freight. Another characteristic that megaregions also often share are threats from naturallyoccurring and manmade disasters. This paper describes a project to better understand, prepare for, and respond to catastrmophic disasters in megaregions In the research, a mass evacuation of the United States Gulf Coast megaregion was modeled based on past hurricane scenarios in the area. The results of the analyses revealed how operational characteristics of the megaregion road network vary and how strategies such as temporally-phased evacuations and regional contraflow operations are able increase overall system effectiveness. The results of the simulations also showed numerous limitations of the network as well as existing modeling and computational processing capabilities to create such simulations.
\end{abstract}

Keywords: Megaregion, Evacuation, Traffic Simulation, Regional Planning

\section{Introduction}

The significant and continuous growth of urbanized areas throughout the world has led to the emergence of the phenomenon of megaregions. Megaregions are broadly defined as chains of once separate cities and metropolitan areas that have grown together to form continuously populated areas over wide geographic expanses [1]. Existing megaregions in Asia, Europe, and North America already spread over hundreds of miles and cross national boundaries. Although they may span separate governmental jurisdictions, megaregions often share common historical, cultural, environmental, and topographic/geologic systems. Because of this they also often have close economic ties, which are themselves facilitated by transportation linkages that connect the movement of people and freight. Another characteristic that megaregions also often share are threats from naturally-occurring and manmade disasters. This is particularly true for megaregions that have developed along oceanic coasts. The past decade, in particular, has seen numerous disasters that have impacted megaregions worldwide, including hurricanes, floods, and natural disasters like the Fukushima Dai-Ichi/Tsunami disaster in Japan. 
To better understand, prepare for, and respond to catastrophic disasters in megaregions emergency preparedness approaches have shifted toward philosophies of resiliency. Disaster resilience seeks to reduce the probability and consequences of disasters while also attempting to minimize the amount of time need to restore systems to normal operation. One recent research effort along these lines has included a series of projects to create a megaregion transportation network for the purpose of simulating the processes and impacts of a mass evacuation within it [2]. As part of that research, a mass evacuation of the United States Gulf Coast megaregion was modeled using a traffic demand generation process that created a spatial and temporal distribution of departure times, origins, and destinations based on past hurricane scenarios in the area.

The results of the analysis associated with that research revealed the operational characteristics of the road network under a variety of threat conditions and demand and capacity management strategies at high spatio-temporal resolution. The study also demonstrated how various strategies such as temporally-phased evacuations and regional contraflow operations were able increase overall system effectiveness. The results of the simulations also showed numerous limitations of the network as well as existing modeling and computational processing capabilities to create such simulations.

To address the large computational time requirements needed to run evacuation models for megaregions, this study explores the application of large-scale traffic simulation modeling techniques to explore properties of Megaregion evacuation traffic at mesoscopic scales. These types of analyses can be used to permit quick and agile evaluations of various road management strategies and can be applied similarly to predict impacts of future anticipated growth and development within large regions and their relationship to emergency travel conditions as well as for the evaluation of varying hazard conditions and their interrelationships between behavioral response and regional transportation management strategies.

\section{Background}

Megaregions are continuously populated areas that have grown together over time from distinctly separate individual cities or populated areas to form continuously densely populated areas that may span over many hundreds of miles. This concept was originally used by Jean Gottmann [1], to describe the continuous metropolitan area along the eastern seaboard of the U.S. Although there is no systematic method to define megaregions, Richard Florida [3] used a global dataset of nighttime light emissions to produce an objectively consistent set of megaregions. These 40 megaregions had an economic output of more than $\$ 100$ billion producing 66 percent of total world output of goods and 85 percent of global innovation.

Paralleling the growth of megaregions, there has been a growing consensus that the earth is experiencing significant climatologically changes [4]. These changes are thought to be contributing to the melting of ice caps, raising of the sea levels, and increasing the frequency and intensity of hurricanes that threaten coastal regions throughout the world. When the trends of climate change and population growth are combined, it appears inevitable that there will also be a significant increase in the number of catastrophic disasters that can threaten millions of people. The 2012 Hurricane Sandy event, for example, threatened 50 million people and killed more than 66 persons. In addition, the hurricane caused widespread power outages; air, rail, and bus transit shut downs; and the evacuation of 375,000 people from lowlying coastal areas [5].

Over the past several decades an iterative series of increasingly more sophisticated and detailed techniques have been applied to better prepare for evacuations of large regional areas. 
Early studies seeking to apply traffic simulation models for evacuations were limited in their geographical scales and time durations. Many initial studies conducted with microscopic simulation were concentrated on small networks over time spans of 12 to 20 hours. Several of these focused on design of contraflow crossovers [6 and 7] and the evaluation of evacuation routes $[6,8,9]$ and impacts on small urban signal networks [10 and 11]. Larger regional networks have been analyzed using macroscopic traffic modeling [12, 13, 14]. These analyses led to conclusions regarding approximate evacuation clearance time and delays. However, no understanding regarding bottlenecks and traffic impacts could be gained due to the low resolution of the models. Most of these evacuation models were not calibrated or validated, and often they were calibrated for normal day traffic with various rough assumption regarding emergency traffic conditions. This was due to the difficulty in acquiring data during actual evacuations to calibrate the networks.

Chiu et al., [15] as well as Dixit et al., [16] conducted regional scale simulation studies to evaluate regional impacts of various evacuation strategies for the Houston-Galveston area during Hurricane Rita and the Louisiana region during hurricane Katrina respectively. However, there is limited research concerning modeling and analysis of megaregion evacuations. Wolshon et al., [17] modeled the New Orleans region of southeast Louisiana evacuation and characterized the measures of effectiveness based on macroscopic measures for varying travel demand and evacuation management strategies.

\section{Research Goals, Approach, and Contributions}

The goal of this study was to develop macroscopic network performance functions for the analysis of evacuation of the Gulf Coast Megaregion of the United States. This function sought to provide a quantitative relationship between macroscopic measures of effectiveness in evacuation network and demand which resulted form various capacity management (contraflow) and demand management (phased) evacuation plans. It is theorized here that these functions provide rapid and useful insights regarding the effectiveness of megaregion evacuation for various storm threat-response scenarios.

To gain insights into the macroscopic traffic characteristics of megaregion-scale emergency traffic processes, this paper presents the results of multiple traffic simulation experiments that featured conditions associated with a variety of scenarios. Each of them varied in the duration of evacuation as well as evacuation plans used and orders issued for the Gulf Coast megaregion. Simulation output were extracted and analyzed, similar to that discussed in Zhang and Wolshon [2]. However, there are several methods to analyze the effectiveness of evacuation plans and several of these have been discussed in [9 and 16] that use "vehicles unable to enter a network during an evacuation" as a measure of effectiveness. This study utilizes "Removed Vehicles" (from the simulation computational process) and" Average Travel Speed" as measures of effectiveness. Both of these were found to be sensitive to evacuation demand generation and the application of contraflow operational plans.

This paper describes the processes and assumptions used to construct and execute the network performance function as well as the results that were gained from it. Perhaps more importantly, this paper provides an analytical framework for forecasting network performance based evacuation simulation data set. The rationale and basis for the functions used here can also be applied more generally, both to other locations, including megaregions in other parts of the world and threat conditions ranging from hurricanes and typhoons to tsunamis, floods, and other types of man-made disasters. This work also summarizes many valuable lessons learned during the development process, including techniques that were found to be 
particularly useful, limitations and difficulties that were not able to be overcome, and a ways of combining simulation results and mathematical approach to gain knowledge about megaregion network performance under evacuation scenarios.

\section{Data, Analyses, and Results}

This research was carried out based on a megaregion evacuation based model developed by Zhang, et al. [2], using a series of theoretical storms. Four critical steps (Network Construction, Evacuation Demand Estimate, Routing and Microscopic Simulation, Calibration and Validation) were conducted to simulate the process of mass evacuation in the Gulf Coast Megaregion. As demonstrated in a recent research by Montz and Zhang [19], the base model was calibrated and validated, and thus it was considered being able to reproduce the evacuation phenomena well.

Once the base model was calibrated and validated, a series of threat-response scenarios, listed below and shown graphically in Figure 1, were based to varying degrees on several prior hurricane events in the Gulf, some recent and others that took place more than 100 years ago.

- Scenario 1: The storm development and track of Hurricane Gustav in 2008

- Scenario 2: Hurricane Gustav increased to Category 4 strength

- Scenario 3: Hurricane Gustav increased to Category 5 strength

- Scenario 4: A Category 4 storm based on an 1867 unnamed hurricane with a forecast uncertainty that threatened the full Gulf Coast study area.

- Scenario 5: A Category 4 storm based on a 1914 unnamed hurricane, traveling from east to west with a forecast uncertainty that threatens the full Gulf Coast study area.

- Scenarios 6: A Category 5 version of the Scenario 5 event.

Using these six hurricane scenarios, evacuation demand were estimated using the time dependent sequential logit model and multinomial logit model, the total demand can be seen in a recent research [2]. For example, nearly 1 million evacuation vehicles were generated in scenario 1 and 4.2 million evacuation vehicles were generated in scenario 4 .

In this paper the focus is on the interrelationships of the evacuation behavioral responses created by these events as they relate to the differences in evacuation travel demand generation based on the evacuation orders and the management of traffic resulting from the implementation of regional contraflow traffic management plans. To this end the network performance was analyzed from the standpoint of two main measures of effectiveness: number of removed vehicles and average speed. In addition, we explore various bottleneck conditions using microscopic speed profiles. In the sections that follow the key indicators performance related to these scenarios and the application of the TRANSIMS system used to simulate them are discussed. 


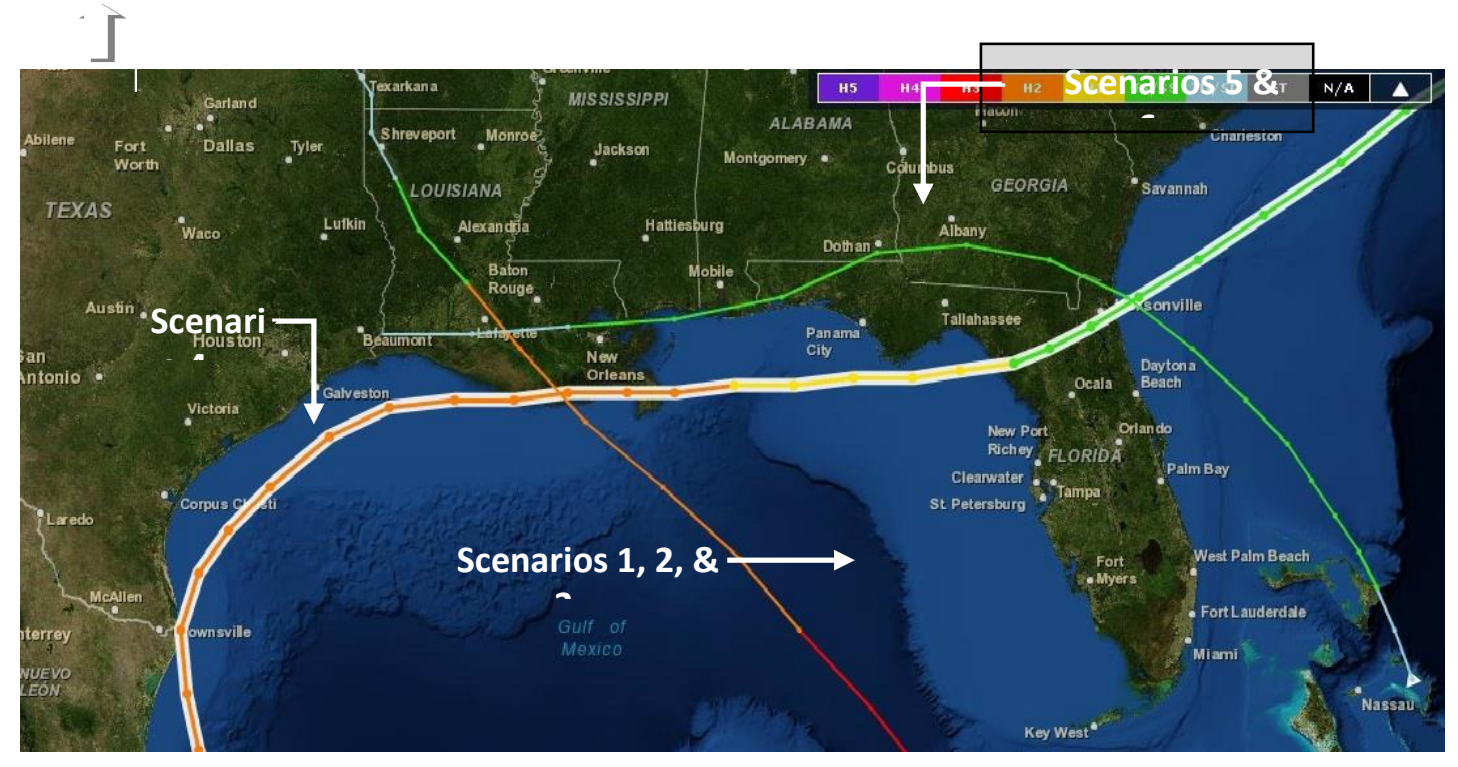

Figure 1. Hurricane Track Scenarios

\subsection{Computing Requirements and Limitation}

To build the model within TRANSIMS, several basic data items, including household distribution and evacuation traffic demand were used as inputs for the program to produce dynamic origin and destination pairings. Next, the TRANSIM ConvertTrips module was applied to disaggregate the demand and load the traffic onto the road network. Then, TRANSIMS Router and MicroSimulator modules were used to route and simulate the evacuation processes in each scenario. As the demand was extremely large by most simulation standards, the computational processing times were quite lengthy; even using a relatively powerful desktop computer. The configuration for the computer used for this study included:

- CPU : Intel Xeon i $52620(6$ core $) * 2$

- $\quad$ RAM : $16 \mathrm{~GB}$

- Hard Disk : 120 SSD for main drive and 2TB SATA for storage

- Mainboard : Asus 6760

- Geography Card : SAPPHIRE Radeon HD 7850 11200-01-20G Video Card OC

Based on this configuration, the computing time for each of the test scenarios [2] are shown in Table 1. From the table it can be seen that as the sizes of the evacuations grew (see: evacuation demand), more iterations and computing times were needed to reach a user equilibrium. Similarly, it is apparent that when the demand was extremely large (above 4 million vehicles as shown in Scenario 4), the computer was unable to accommodate the simulation and the computational process was spontaneously aborted.

To overcome the limitations of computational capability, the evacuation process for Scenario 4 was required to be simulated separately using two sub-areas runs. The results of these combined runs are shown as a single scenario run in Table 1. The first area was the Houston-Galveston region and the other covered the region from Beaumont to New Orleans. 
Since no traffic from Houston moved substantially to the eastern region and vice versa, the results of the change were significant and permitted the simulations to be run without failure.

Table 1. Computational Processing Time

\begin{tabular}{|c|c|c|c|}
\hline Scenario & $\begin{array}{c}\text { Number of } \\
\text { Iterations }\end{array}$ & $\begin{array}{c}\text { Evacuation } \\
\text { Demand (veh) }\end{array}$ & $\begin{array}{c}\text { Total } \\
\text { Computing Time } \\
\text { (hh:mm:ss) }\end{array}$ \\
\hline 1a & 55 & 997,891 & $85: 16: 36$ \\
\hline 1b & 60 & 997,891 & $88: 24: 42$ \\
\hline 1c & 55 & 997,891 & $88: 45: 07$ \\
\hline 2a & 51 & $1,122,071$ & $93: 58: 30$ \\
\hline 2b & 52 & $1,122,071$ & $95: 37: 29$ \\
\hline 2c & 45 & $1,122,071$ & $96: 10: 05$ \\
\hline $3 a$ & 79 & $1,215,244$ & $95: 30: 00$ \\
\hline $3 b$ & 44 & $1,215,244$ & $104: 57: 10$ \\
\hline $3 c$ & 44 & $1,215,244$ & $133: 53: 47$ \\
\hline 4 & 91 & $4,026,661$ & $207: 46: 64$ \\
\hline 5 & 36 & 903,688 & $98: 37: 00$ \\
\hline 6 & 50 & $1,238,327$ & $137: 35: 43$ \\
\hline
\end{tabular}

\subsection{Data}

As discussed in a previous work [2], the use of contraflow on a region-wide basis significantly improved the progression of traffic in Scenario 1. However, the incremental benefit of its use diminished as time extended later into the evacuation and the overall evacuation traffic demand dropped. It was also shown that under other scenarios (such as Scenario 3), the incremental benefit of contraflow plan was higher.

Several contraflow plans are built based on the southwest contraflow plan and southeast contraflow plan of Louisiana and the contraflow plan for Texas in Gustav. As shown in Table 2 and Figure insets $2 \mathrm{a}$ and $2 \mathrm{~b}$.

Contraflow Plan 1 in the test simulations was derived from the Louisiana Department of Transportation and Development's actions during the 2008 Hurricane Gustav evacuation of south Louisiana. Contraflow was applied on several strategic links starting at 4:00am, on the second day of the two-day Gustav evacuation. The operational time period of contraflow on each link is listed in Table 2 and presented graphically in Figure 2. The location of Contraflow Plans 2 and 3 were the same as Contraflow Plan 1. However, the use of contraflow operations were extended from 12 hours in Plan 1, to 40 hours in Plan 2, and then to 48 hours in Plan 3.

To investigate the sensitivity of demand and the implementation of contraflow management plans on network performance, multiple one-day evacuation simulations were performed. The three contraflow plans were executed for different scenarios (shown in the "CF Plan " column of Table 2). All the experiments shared the same departure curve as in the first day of Scenario 2. Because all the experiments picked shared the same destination choice and evacuation areas, such comparisons were significant. The network performance parameters were aggregated with the two-day evacuation simulations from Scenario 1 to Scenario Three, as shown in Table 3. 
Table 2. Contraflow Plan Implementation in the Simulations

\begin{tabular}{|c|c|c|c|}
\hline Road Name & Start Time & End Time & Contraflow Plan \\
\hline $\begin{array}{c}\text { Eastbound I-10 between } \\
\text { New Orleans to Laplace, } \\
\text { LA }\end{array}$ & $\begin{array}{c}\text { 4:00 am, Second day of } \\
\text { evacuation }\end{array}$ & $\begin{array}{c}\text { 4:00 pm, Second day of } \\
\text { evacuation }\end{array}$ & \multirow[t]{4}{*}{ Plan 1} \\
\hline $\begin{array}{c}\text { Northbound I-10/I-55 } \\
\text { between Hammond, LA } \\
\text { and Mississippi }\end{array}$ & $\begin{array}{c}\text { 4:00 am, Second day of } \\
\text { evacuation }\end{array}$ & $\begin{array}{c}4: 00 \mathrm{pm}, \text { Second day of } \\
\text { evacuation }\end{array}$ & \\
\hline $\begin{array}{l}\text { Northbound I-59, north } \\
\text { for the I-10/I-12/I-59 } \\
\text { interchange }\end{array}$ & $\begin{array}{c}\text { 4:00 am, Second day of } \\
\text { evacuation }\end{array}$ & $\begin{array}{c}6: 30 \mathrm{pm}, \text { Second day of } \\
\text { evacuation }\end{array}$ & \\
\hline $\begin{array}{l}\text { Northbound I-49, on } \\
\text { I-10 }\end{array}$ & $\begin{array}{c}\text { 4:00 am, Second day of } \\
\text { evacuation }\end{array}$ & $\begin{array}{c}12: 30 \mathrm{pm}, \text { Second day of } \\
\text { evacuation }\end{array}$ & \\
\hline $\begin{array}{l}\text { Eastbound I-10 between } \\
\text { New Orleans to Laplace, } \\
\text { LA }\end{array}$ & $\begin{array}{c}\text { 4:00 am, first day of } \\
\text { evacuation }\end{array}$ & $\begin{array}{c}\text { 12:00 am, Second day of } \\
\text { evacuation }\end{array}$ & \multirow[t]{4}{*}{ Plan 2} \\
\hline $\begin{array}{c}\text { Northbound I-10/I-55 } \\
\text { between Hammond, LA } \\
\text { and Mississippi }\end{array}$ & $\begin{array}{c}\text { 4:00 am, first day of } \\
\text { evacuation }\end{array}$ & $\begin{array}{c}\text { 12:00 am, Second day of } \\
\text { evacuation }\end{array}$ & \\
\hline $\begin{array}{c}\text { Northbound I-59, north } \\
\text { for the I-10/I-12/I-59 } \\
\text { interchange }\end{array}$ & $\begin{array}{c}\text { 4:00 am, first day of } \\
\text { evacuation }\end{array}$ & $\begin{array}{c}\text { 12:00 am, Second day of } \\
\text { evacuation }\end{array}$ & \\
\hline $\begin{array}{l}\text { Northbound I-49, on } \\
\text { I-10 }\end{array}$ & $\begin{array}{c}\text { 4:00 am, first day of } \\
\text { evacuation }\end{array}$ & $\begin{array}{c}\text { 12:00 am, Second day of } \\
\text { evacuation }\end{array}$ & \\
\hline $\begin{array}{c}\text { Eastbound I-10 between } \\
\text { New Orleans to Laplace, } \\
\text { LA }\end{array}$ & $\begin{array}{c}\text { 12:00 am, first day of } \\
\text { evacuation }\end{array}$ & $\begin{array}{c}\text { 12:00 am, Second day of } \\
\text { evacuation }\end{array}$ & \multirow[t]{4}{*}{ Plan 3} \\
\hline $\begin{array}{l}\text { Northbound I-10/I-55 } \\
\text { between Hammond, LA } \\
\text { and Mississippi }\end{array}$ & $\begin{array}{c}\text { 12:00 am, first day of } \\
\text { evacuation }\end{array}$ & $\begin{array}{c}\text { 12:00 am, Second day of } \\
\text { evacuation }\end{array}$ & \\
\hline $\begin{array}{c}\text { Northbound I-59, north } \\
\text { for the I-10/I-12/I-59 } \\
\text { interchange }\end{array}$ & $\begin{array}{c}\text { 12:00 am, first day of } \\
\text { evacuation }\end{array}$ & $\begin{array}{c}\text { 12:00 am, Second day of } \\
\text { evacuation }\end{array}$ & \\
\hline $\begin{array}{l}\text { Northbound I-49, on } \\
\text { I-10 }\end{array}$ & $\begin{array}{c}\text { 12:00 am, first day of } \\
\text { evacuation }\end{array}$ & $\begin{array}{c}\text { 12:00 am, Second day of } \\
\text { evacuation }\end{array}$ & \\
\hline
\end{tabular}

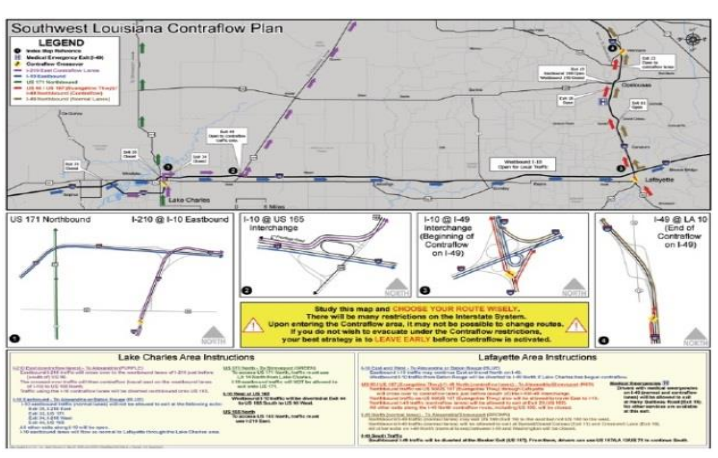

Figure 2a. Southwestern Louisiana

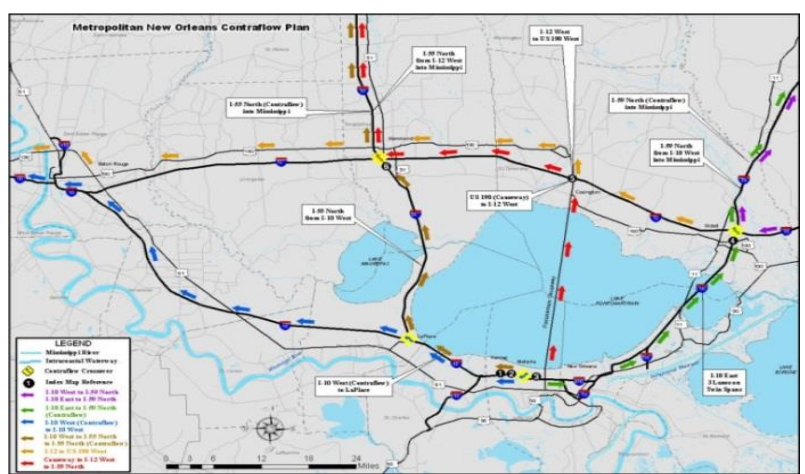

Figure $2 b$. Southeastern Louisiana

Figure 2. Louisiana Deprtment of Transportation and Development Emergency Evacuation Interstate Contraflow Evacution Management Plans 
Table 3. Network Performance Simulation Results ( $24 \mathrm{hrs}$ and 48hrs)

\begin{tabular}{|c|c|c|c|c|c|c|c|}
\hline Scenario & $\begin{array}{l}\text { Total } \\
\text { Trips }\end{array}$ & $\begin{array}{c}\text { Total } \\
\text { Vehicle Miles }\end{array}$ & $\begin{array}{c}\text { Total } \\
\text { Vehicle } \\
\text { Hours }\end{array}$ & $\begin{array}{c}\text { Ave Travel } \\
\text { Speed(mph) }\end{array}$ & $\begin{array}{l}\text { Removed } \\
\text { Vehicles }\end{array}$ & $\begin{array}{c}\text { CF } \\
\text { Plan }\end{array}$ & Note \\
\hline $2 d$ & 451,930 & $51,714,704$ & 990,090 & 52.23 & 8,483 & 1 & 24 hours \\
\hline $2 g$ & 494,654 & $56,636,072$ & $1,157,487$ & 48.93 & 13,327 & 1 & 24 hours \\
\hline $2 f$ & 584,602 & $66,734,865$ & $1,570,675$ & 42.49 & 33,740 & 1 & 24 hours \\
\hline $2 \mathrm{e}$ & 674,518 & $75,781,434$ & $2,438,406$ & 31.08 & 67,801 & 1 & 24 hours \\
\hline $2 \mathrm{~d} 2$ & 454,173 & $52,037,891$ & $1,079,586$ & 48.20 & 8,478 & 2 & 24 hours \\
\hline $2 \mathrm{~g} 2$ & 494,654 & $56,716,047$ & $1,279,575$ & 44.32 & 12,732 & 2 & 24 hours \\
\hline $2 \mathrm{f} 2$ & 584,602 & $67,185,618$ & $1,639,260$ & 40.99 & 27,042 & 2 & 24 hours \\
\hline $2 \mathrm{e} 2$ & 674,518 & $76,054,219$ & $2,383,907$ & 31.90 & 69 , & 2 & 24 hours \\
\hline $2 \mathrm{~d} 3$ & 454,173 & $52,074,389$ & $1,074,445$ & 48.47 & 7,889 & 3 & 24 hours \\
\hline $2 g 3$ & 494,654 & $56,712,861$ & $1,276,416$ & 44.43 & 13,153 & 3 & 24 hours \\
\hline $2 \mathrm{f3}$ & 584,602 & $66,651,559$ & $1,597,052$ & 41.73 & 25,000 & 3 & 24 hours \\
\hline $2 \mathrm{e} 3$ & 674,518 & $75,939,893$ & $2,537,287$ & 29.93 & 68,294 & 3 & 24 hours \\
\hline $1 a$ & 997,891 & $106,748,968$ & $2,611,951$ & 40.87 & $79,402.41$ & 1 & 48hours \\
\hline $1 b$ & 997,891 & $108,852,046$ & $2,660,963$ & & $55,431.00$ & 2 & 48hours \\
\hline $1 c$ & 997,891 & $108,901,028$ & $2,672,603$ & 40.75 & $61,401.00$ & 3 & 48hours \\
\hline $2 a$ & 1122071 & $117,803,422$ & $2,990,495$ & 39.39 & $98,002.67$ & 1 & 48hours \\
\hline $2 b$ & 1122071 & $119,787,151$ & $3,349,147$ & 35.77 & $89,026.11$ & 2 & 48hours \\
\hline $2 c$ & 1122071 & $119,924,893$ & $3,370,999$ & 35.58 & $91,270.25$ & 3 & 48hours \\
\hline $3 a$ & 1215244 & $127,527,475$ & $3,520,007$ & 36.23 & $158,069.00$ & 1 & 48hours \\
\hline $3 b$ & 1215244 & $128,852,536$ & $3,927,447$ & 32.81 & $148,826.48$ & 2 & 48hours \\
\hline $3 c$ & 1215244 & $130,515,376$ & $4,141,751$ & 31.51 & $117,230.13$ & 3 & 48hours \\
\hline
\end{tabular}

\section{Analysis}

The simulations suggested that two parameters, "Number of Vehicles Removed" and "Average Travel Speed", were the most significant factors related to network performance during evacuations. "Number of Vehicles Removed" is a output parameter measure produced by a TRANSIMS simulation to account for vehicles which experience a travel time three hours longer than under normal conditions. When this occurs, TRANSIMS removes vehicles (RV) from the simulation process. While this would never occur in the real world, it is a helpful measure in simulation coding and error-checking perspective because it indicates where routes may not be connected properly or where signals have been mistimed. Since vehicle removal may also be indicative of the excessive congestion in the network the location and timing of vehicle removals can also be used to identify bottleneck locations in which congestion and queuing results in in unrealistic and inordinately long travel times.

\subsection{Number of Vehicles Removed}

Plots of demand and number of vehicles removed under different contraflow plans for the one day evacuation as well as two days evacuation were shown in Figure 3. The shape of the curve is similar in nature to a "power curve" used to measure the power generation capability of a device relative to its input energy requirements. In this application, the curves compare the number of vehicles removed from the simulation as a function of the amount of vehicles generated in the evacuation scenarios. In the figures, a one-day evacuations that generated 
demand above 0.55 million, the network performance deteriorated significantly. In contrast, the threshold demand for two-day evacuation was 1.1 million vehicles. As the demand increased above these critical values, the number of vehicles removed from the simulations jumped to high values more than 10,000 vehicles, or ten percent of the total demand, were removed as the road network congestion. From these qualitative analyses several findings emerge from the Figure 3 curve plots.

Fundamentally, as demand rose, number of vehicles increased. However, the curves became less linear when demand exceeded 0.55 million for one-day and 1.1 million for twoday evacuations. The curve for shorter durations of contraflow was above the curve for longer contraflow plan usage. This suggested that longer contraflow usage allowed more people successfully get out of threaten area. Also apparent in these curve figure was that the benefits of contraflow differed notably between one- and two-day evacuations and that Contraflow Plans 2 and 3 had nearly the same effect on the evacuation process.

The incremental benefit of contraflow can also be seen in the use of Plan 2 over Plan 1 for one-day evacuations where the curve was raised from zero to a peak value for demand ranging from 0.49 million to 0.58 million vehicles, while the benefit is negligible for demand ranging from 0.58 million to 0.67 million. This suggests that longer contraflow durations yielded little benefit over shorter contraflow use when the demand was near or above 0.67 million vehicles. For two-day evacuations, the benefit of Contraflow Plan 2 over Plan 1 decreased when evacuation travel demand exceeded 1.1 million vehicles. However, the effect of longer contraflow utilization (Contraflow Plan 3) increased (curve three) when demand exceed 1.1 million vehicles.

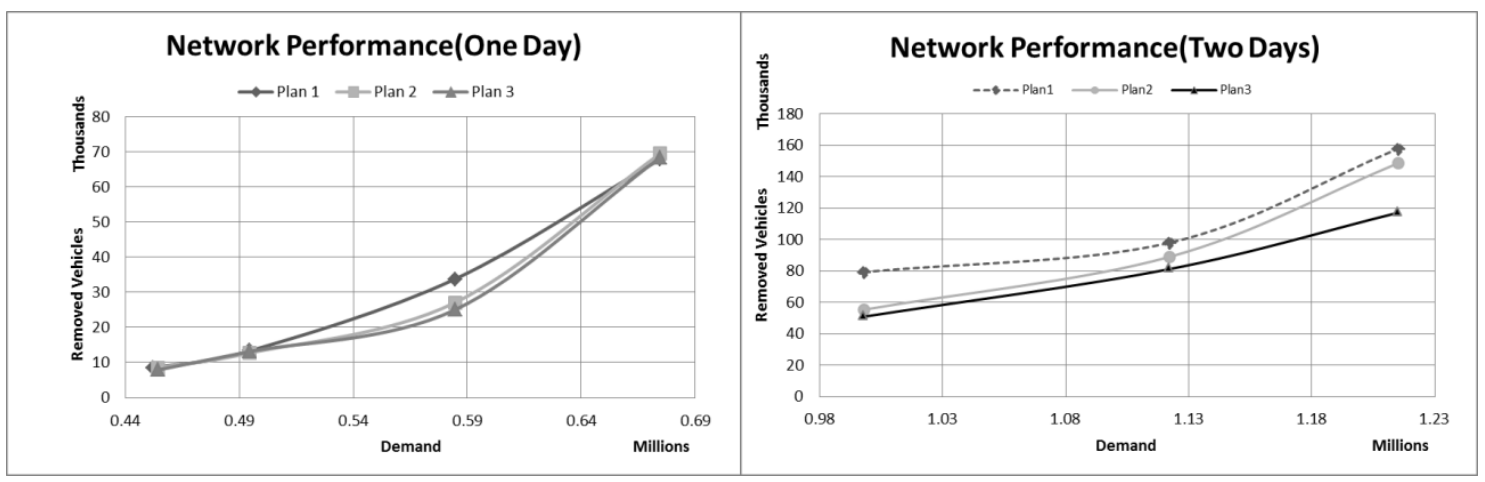

Figure 3. Network Performance (Left: One Day, Right: Two Days)

To investigate how demand and contraflow plan implementation effected megaregion network performance, a mathematical method (curve fitting) was used to find out the function for removed vehicles. The function was created using the process described below.

The function for one day and two days evacuation were the same and followed the now familiar power curve shape. The equation to describe this general conditions was:

$$
F(x)=a^{*}\left(x^{b}\right)+c
$$

where,

$F(x)$ : number of vehicles removed (10,000 vehicles)

$x$ : demand (100,000 vehicles) 
$a$ : contraflow parameter; as $\boldsymbol{a}$ decreases in respond to prolonged contraflow plan

$b$ : evacuation demand and network parameter; reflects the trend of removed vehicles in response to total demand. A power function indicates that the removed vehicles changed slowly with increased demand, and then increased fast after the demand crossed one constant value.

c: shifted value of the function; denotes that removed vehicles do not change when the demand was small.

The coefficients used in this research and the statistics of there resultant effects are shown in Tables 4 and 5. The value of parameter "a" did not follow any trend in respond to demand and contraflow plans and the 95 percent confidence bounds were null from Model 1 to Model 3 . As the b-value changed between 4 and 10.36. To get a more standard function, parameter "b" was set as 4,5 , and 6 , respectively.

The Coefficients and statistics showed that when " $b$ " was set as 4 , the function seems more reasonable. The coefficient "a" decreased as contraflow plan was used for two-day evacuation models. However, this parameter did not show significant variation for one-day evacuation models. Such statistics are consistent with logical intuition, in that the influence of contraflow for multi-day evacuations over single-day evacuations in significant, and a longer contraflow usage permits more people to safely evacuate from endangered area; shown as less vehicles removed.

Table 4. Power Curve Coefficients and Result Statistics

\begin{tabular}{|c|c|c|c|c|c|c|c|}
\hline \multirow{2}{*}{ Model } & \multicolumn{3}{|c|}{ Coefficients } & \multicolumn{2}{c|}{ Statistics } & $\begin{array}{c}\text { Evac } \\
\text { Duration }\end{array}$ \\
\cline { 2 - 7 } & $\mathbf{a}$ & $\mathbf{9 5 \%}$ confidence bounds & b & c & R-square & RMSE & two days \\
\hline 1 & $3.333 \mathrm{e}-11$ & Null & 10.36 & 8.939 & 0.7920 & Null & two \\
\hline 2 & $1.696 \mathrm{e}-10$ & Null & 9.950 & 4.270 & 0.9984 & Null & two days \\
\hline 3 & $5.46 \mathrm{e}-6$ & Null & 5.764 & 1.967 & 1.0000 & Null & two days \\
\hline 4 & 0.009831 & $(-0.06851,0.08817)$ & 4.652 & -2.83 & 0.9695 & 0.4706 & one day \\
\hline 5 & $2.937 \mathrm{e}-5$ & $(-0.0003644,0.0004231)$ & 7.640 & 6.056 & 0.9996 & 0.9629 & one day \\
\hline 6 & 0.00203 & $(-0.003978,0.008037)$ & 5.466 & 0.292 & 1.000 & 0.2518 & one day \\
\hline
\end{tabular}

Table 5. Power Curve Coefficients and Result Statistics

\begin{tabular}{|c|c|c|c|c|c|c|c|}
\hline \multirow{2}{*}{ Model } & \multicolumn{4}{|c|}{ Coefficients } & \multicolumn{2}{c|}{ Statistics } & Evac Duration \\
\cline { 2 - 7 } & $\mathbf{a}$ & $\mathbf{9 5 \%}$ confidence bounds & $\mathbf{c}$ & R-square & RMSE & \\
\hline 1 & 0.0006616 & $(-0.001887,0.00321)$ & & 0.6897 & 0.9158 & 1.687 & two days \\
\hline 2 & 0.0007854 & $(-0.0008202,0.002391)$ & & -2.679 & 0.9748 & 1.063 & two days \\
\hline 3 & 0.0005569 & $(0.0002135,0.0009002)$ & & -0.5148 & 0.9977 & 0.2273 & two days \\
\hline 4 & 0.03625 & $(0.03244,0.04006)$ & & -7.713 & 0.9988 & 1.141 & one day \\
\hline 5 & 0.03698 & $(0.01934,0.05461)$ & & -9.908 & 0.976 & 5.277 & one day \\
\hline 6 & 0.03731 & $(0.02958,0.04504)$ & & -9.154 & 0.9954 & 2.314 & one day \\
\hline
\end{tabular}

When this data is presented graphically as shown in the charts of Figure 4, the results of these analyses can be compared quantitatively. As shown in the figures, the curves developed for Models 1 through 3 are below the curves for Models 4 through 6. These finding logically correspond because the congestion for the two-day evacuations were less than the one-day events for the same evacuation demand. However, it is also apparent in the figures that the megaregion network was not able to serve demands greater than 1.5 million in a single day. 
For evacuations involving more than half a million vehicles, evacuations can be more effectively accomplished in two days rather than in one. This can be seen graphically in the figure where the "removed vehicles" curve for the one-day event increases significantly for demands exceeding half a million vehicles and much higher than the two days curve.

It is also apparent in the figures that when the demand is below 1 million for a two-day evacuation, a short- to no- contraflow plan is needed because the benefit of contraflow is negligible. When demand exceeds 1.1 million vehicles, however, a longer contraflow plan is seen to be considerably more desirable based on overall network performance.

From these combined findings, it can be inferred that the network capacity for the Gulf Coast megaregion network is effectively half a million vehicles for a one-day evacuation and somewhere between 1.0 to 1.1 million for a two-day evacuation. These results further suggest that for any demand below these threshold values, no contraflow plan is needed. However, when the demand is above these critical threshold values, contraflow operations have a significant beneficial impact. For any potential evacuation demand in this region, the evacuation time and need for implementation of contraflow could also be estimated from removed vehicles model curve in Figure 3 and corresponding management strategies for the various scenarios is shown in Table 6.
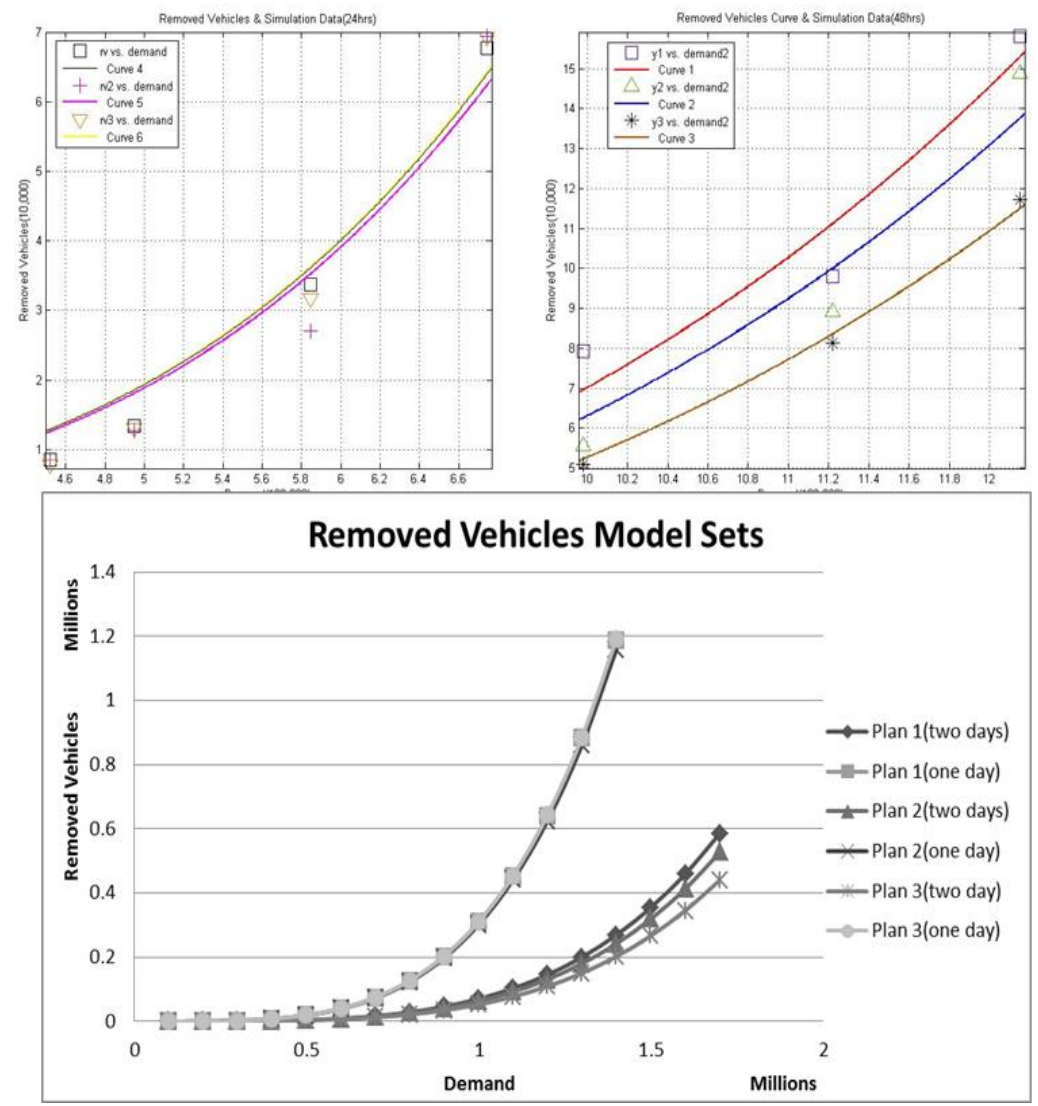

Figure 4. Curve Fitting Results for Simulation Data (Left: Two days, Right: One day, Lower: Model Sets) 
Table 5. Suggested Evacuation Management Plan

\begin{tabular}{|c|c|c|}
\hline Demand & Evacuation Time & Contraflow \\
\hline$<0.5$ million & One Day & none or Plan 1 \\
\hline $0.5-0.58$ million & One Day & Plan 3 \\
\hline $0.58-1.0$ million & Two Days & Plan 2 \\
\hline $1.0-1.1$ million & Two Days & Plan 3 \\
\hline above 1.1 million & Two Days & \\
\hline
\end{tabular}

To better visualize the incremental benefits of contraflow operations for the various evacuation demands, speed plots based on a microscopic speed data produced by TRANSIMS were developed. Thermal charts revealing speed in terms of temperature color are shown in Figure 6. In these plots for Scenarios $2 b, 2 c, 3 b$, and $3 c$ travel speeds are shown over time (yaxis) and distance (x-axis) using hot colors (red/yellow) for slow travel and cool colors (green) for fast travel on Interstate 10 near New Orleans.

Comparing the corresponding upper and lower charts on the right and left sides of the figure, the incremental benefit of Contraflow Plan 3 over Contraflow Plan 2 can be seen. Contrasting the two upper graphics, the negligible effect of contraflow in Scenario 2 can also be seen. The color patters of these two graphs are effectively the same. In the side-by-side comparison of Scenarios $3 \mathrm{~b}$ and $3 \mathrm{c}$, the red and orange areas are diminished in the left side lower left, which is the graph representing Figure $3 \mathrm{~b}$. This represents the benefits of longer contraflow durations for 1.2 million vehicles over 1.1 million vehicles.
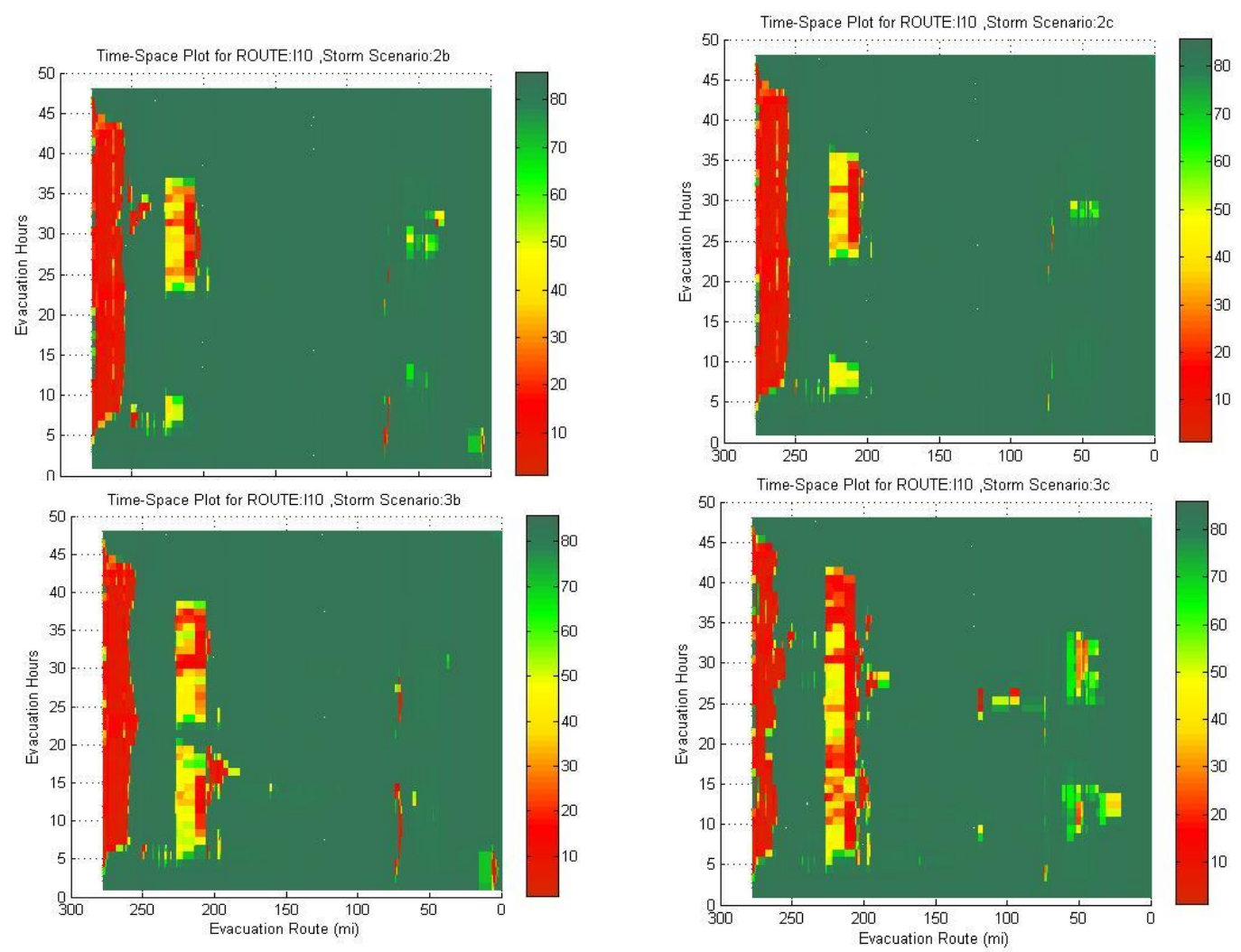

Figure 6. Speed Plots for Westbound Interstate 10 out of New Orleans (upper left: Scenario 2b, upper right: Scenario 2c, lower left: Scenario 3b, lower right: Scenario 3c) 
Similar phenomena can be seen in plots for the Interstate 55 corridor spanning the border area connecting Louisiana and Mississippi in Figure 7.
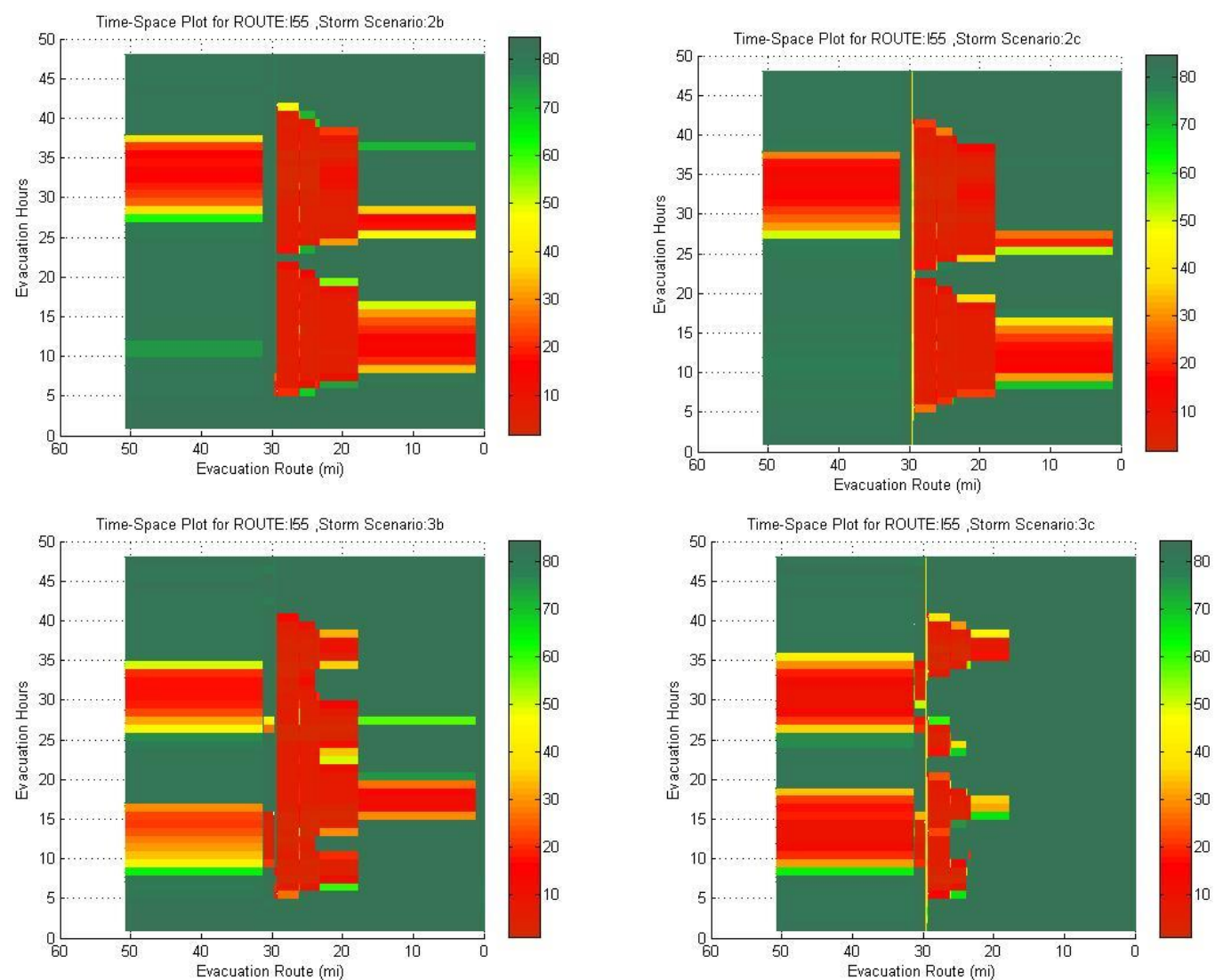

Figure 7. Speed Plots for Northbound Interstate 55 (upper left: Scenario 2b, upper right: Scenario 2c, lower left: Scenario 3b, lower right: Scenario 3c)

\subsection{Average Travel Speed}

In addition to the qualitative analyses of contraflow using speed data discussed above, quantitative assess assessments of speed performance were also undertaken as part of this research. Among the general, and logically expected, findings from the qualitative review were that:

- average travel speeds decreased when evacuation demand increased;

- average travel speeds decreased when contraflow utilization was lengthened;

- the beneficial effects of contraflow on average travel speed was more considerably more pronounced during two-day evacuations when compared to single-day evacuations; and

- contraflow benefits increased most notably when demand exceeded a threshold value of at least 1.1 million vehicles over two days. 
To begin the qualitative analyses, curve-fitting methods were once again applied to estimate the function for average travel speed. The general equation for this function is listed below.

$$
v(x)=\alpha * x^{\beta}+v_{f}
$$

In the equation, $v_{f}$ is the average free flow speed. The parameter $\alpha$ is a negative number closely related to the use of contraflow. $\mathrm{x}$ is the demand in terms of 100,000 vehicles and similar to what was used previously in the analysis of removed. $\beta$ is a constant value, which varied around a value of 4 . To achieve a more standard function, $\beta=4$ was used in this research.

This function indicated that the average travel speed for the whole network can effectively be determined using the average network free flow speed, evacuation demand and contraflow plan. Coefficients for Equation (2) are shown in Table 5. $R$ square parameters were all above 0.94 , suggesting a reasonable fit between the functions and simulation data.

Table 6. Speed Function Coefficients and Statistics

\begin{tabular}{|c|c|c|c|c|c|c|c|c|}
\hline \multirow[t]{2}{*}{ Model } & \multicolumn{5}{|c|}{ Coefficients } & \multicolumn{2}{|c|}{ Statistics } & \multirow{2}{*}{$\begin{array}{c}\text { Evac. } \\
\text { Duratio } \\
\mathbf{n}\end{array}$} \\
\hline & $\alpha$ & $\begin{array}{l}\text { 95\% confidence } \\
\text { bounds }\end{array}$ & $\beta$ & $\begin{array}{c}v_{f} \\
(\mathbf{m p h})\end{array}$ & $\begin{array}{c}95 \% \\
\text { confidence } \\
\text { bounds }\end{array}$ & $\begin{array}{c}\text { R- } \\
\text { square }\end{array}$ & RMSE & \\
\hline 1 & -0.00039 & $(-0.0014,0.0006247)$ & 4 & 45.0 & $(28.2,61.78)$ & 0.9595 & 0.6701 & two day \\
\hline 2 & -0.00068 & $(-0.002035,0.0006729)$ & 4 & 47.3 & $(24.84,69.75)$ & 0.9761 & 0.8961 & two day \\
\hline 3 & -0.00078 & $(-0.001466,-8.78 \mathrm{e}-005)$ & 4 & 48.3 & $(36.84,59.69)$ & 0.9952 & 0.4561 & two day \\
\hline 4 & -0.01253 & $(-0.01428,-0.01078)$ & 4 & 57.0 & $(54.83,59.18)$ & 0.9979 & 0.5231 & one day \\
\hline 5 & -0.00926 & $(-0.0133,-0.00523)$ & 4 & 51.2 & $(46.19,56.22)$ & 0.9799 & 1.207 & one day \\
\hline 6 & -0.01055 & $(-0.01637,-0.004723)$ & 4 & 52.4 & $(45.12,59.6)$ & 0.9681 & 1.743 & one day \\
\hline
\end{tabular}

Graphical plots for the speed model sets are shown in Figure 8. From this information it can be seen that for single day evacuations, average speed begin to decrease once demand exceeds 0.8 million. This suggests a one-day megaregion evacuation system capacity. Similarly, the network cannot accommodate more than 1.5 million vehicles over a two-day evacuation of this region. The data also suggest that Models 1, 2, and 3 work well while demand remains between 0.8 million (one-day) and 1.5 million (two days). Models 4, 5, and 6 only operate effectively when demand is below 0.8 million for a single day.

Using the estimated evacuation demand from the various scenarios, the evacuation time and contraflow plan were also able to be suggested from the average travel speed model curve sets in Figure 6 above and a set of potentially appropriate management strategies for conditions similar to Scenario 1, 2, and 3 is listed in Table 7. 

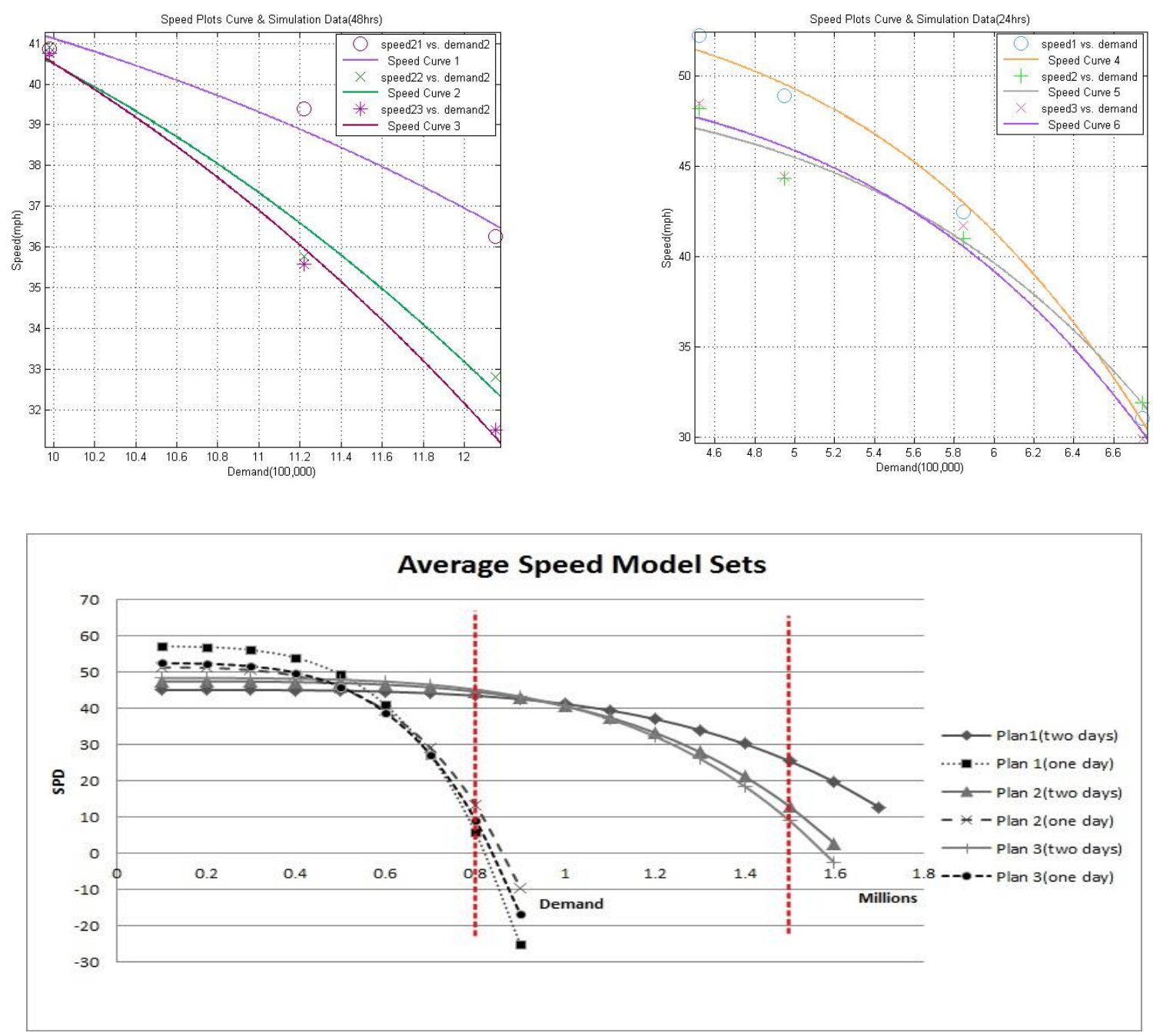

Figure 8. Average Travel Speed Curve

(Left: two days; Right: one day; Lower: Model Sets)

Table 7. Suggested Evacuation Management Plan

\begin{tabular}{|c|c|c|}
\hline Demand & Evacuation Time & Contraflow \\
\hline$<0.5$ million & One Day & no or Plan 1 \\
\hline $0.5-0.8$ million & Two Day & Plan 1 \\
\hline $0.8-1.0$ million & Two Days 1 \\
\hline $1.0-1.1$ million & Two Days & Plan 2 \\
\hline $1.1-1.5$ million & Two Days & Plan 3 \\
\hline Above 1.5 million & More than two days & Plan \\
\hline
\end{tabular}




\section{Validation}

A critical component of any simulation is the calibration and validation of the output results. While a typical validation requires a comparison about adjustment process using some form of real-world baseline data set, the shear magnitude of this model did not permit a useful calibration or validation basis. Thus, it was concluded here that the model results would be used to compare relative differences in model output based on a varying set of input parameters, rather than a validation to real-life data. Similarly, the focus of the validation here was the mathematical functions and their conformance to the simulation model output.

To validate the performance functions of this network, the predictive equations for number of vehicles removed the average travel speed were used. Using an additional set of 15 experiments function 1 and function 2 were validated against cross product sets of five demand groups of 750,000; 900,000; 1,250,000; 1,300,000; and 1,400,000 vehicles; against Contraflow Plans 1, 2 and 3. The validation for the "Removed Vehicles" and "Average Travel Speed" performance measures are shown in Table 8.

The statistics shows that the errors between the model results and simulation results are primarily below five percent with a few within nine to ten percent suggesting that the Network Performance Equations showed a reasonable fit compared to the simulation results and could be deemed to be valid for the purposes of the research.

Table 8. Network Performance Function Validation

\begin{tabular}{|c|c|c|c|c|c|c|c|}
\hline \multirow{2}{*}{$\begin{array}{l}\text { Demand } \\
\text { (vehicles) }\end{array}$} & \multicolumn{2}{|c|}{ Function Results } & \multicolumn{2}{|c|}{ Simulation Results } & \multirow{2}{*}{$\begin{array}{l}\text { Error for } \\
\text { Removed } \\
\text { Vehicles }\end{array}$} & \multirow{2}{*}{$\begin{array}{l}\text { Error for } \\
\text { Travel } \\
\text { Speed }\end{array}$} & \multirow{2}{*}{$\begin{array}{l}\text { Contraflow } \\
\text { Plan }\end{array}$} \\
\hline & $\begin{array}{l}\text { Removed } \\
\text { Vehicles }\end{array}$ & $\begin{array}{c}\text { Average } \\
\text { Speed } \\
\text { (mph) }\end{array}$ & $\begin{array}{l}\text { Removed } \\
\text { Vehicles }\end{array}$ & $\begin{array}{c}\text { Average } \\
\text { Speed } \\
\text { (mph) }\end{array}$ & & & \\
\hline 750,000 & 16,680 & 73.3 & 15,251 & 68.45641 & 0.0856 & 0.0660 & 3 \\
\hline 900,000 & 34,589 & 69.1 & 31,768 & 68.656 & 0.0815 & 0.0061 & 3 \\
\hline $1,250,000$ & 128,710 & 46.9 & 118,609 & 42.24233 & 0.0784 & 0.0990 & 3 \\
\hline $1,300,000$ & 150,573 & 41.7 & 147,874 & 39.81407 & 0.0179 & 0.0460 & 3 \\
\hline $1,400,000$ & 202,529 & 29.5 & 197,046 & 28.1422 & 0.0270 & 0.0455 & 3 \\
\hline 750,000 & 199,627 & 72.2 & 18,379 & 72.10344 & 0.0792 & 0.0017 & 2 \\
\hline 900,000 & 41,393 & 68.5 & 39,376 & 66.87985 & 0.0487 & 0.0241 & 2 \\
\hline $1,250,000$ & 154,028 & 49.1 & 149,285 & 49.00565 & 0.0307 & 0.0015 & 2 \\
\hline $1,300,000$ & 180,191 & 44.6 & 168,428 & 44.16666 & 0.0652 & 0.0089 & 2 \\
\hline $1,400,000$ & 242,366 & 33.8 & 219,679 & 32.00501 & 0.0936 & 0.0538 & 2 \\
\hline 750,000 & 22,192 & 70.0 & 20,823 & 68.01848 & 0.0617 & 0.0286 & 1 \\
\hline 900,000 & 46,018 & 67.9 & 45,774 & 64.72864 & 0.0053 & 0.0469 & 1 \\
\hline $1,250,000$ & 17,1240 & 56.8 & 167,412 & 51.41875 & 0.0223 & 0.0953 & 1 \\
\hline $1,300,000$ & 200,329 & 54.3 & 181,407 & 49.56252 & 0.0944 & 0.0866 & 1 \\
\hline $1,400,000$ & 269,449 & 48.2 & 250,582 & 43.60966 & 0.0700 & 0.0943 & 1 \\
\hline
\end{tabular}

\section{Conclusion}

This work described in this paper has revealed several key aspects of the megaregion evacuation process in the Gulf Coast area of the US as well as for other megaregions in general. Among of the most interesting and potentially the most useful are the relationships between demand generation the use of capacity enhancing techniques like contraflow and 
how they ultimate impact the capacity of megaregion-scale networks. One of the ways that this general finding is illustrated can be seen is in the graphs of Figure 9. In these the trend for removed vehicles and average travel speed are shown to follow opposite direction curve directions.

In addition to the network performance functions ability to demonstrate the megaregion network performance, it also shows the evolution of congestion within megaregion-sized network during an evacuation. They were also useful to illustrate the regional role of contraflow on network performance, especially in estimating its impact on network performance measures like average travel speed and vehicles that are unable to exit the network and reach their intended shelter destinations. They were also helpful in demonstrating the marginal effect of variations in shortening or lengthening the duration of contraflow operations.
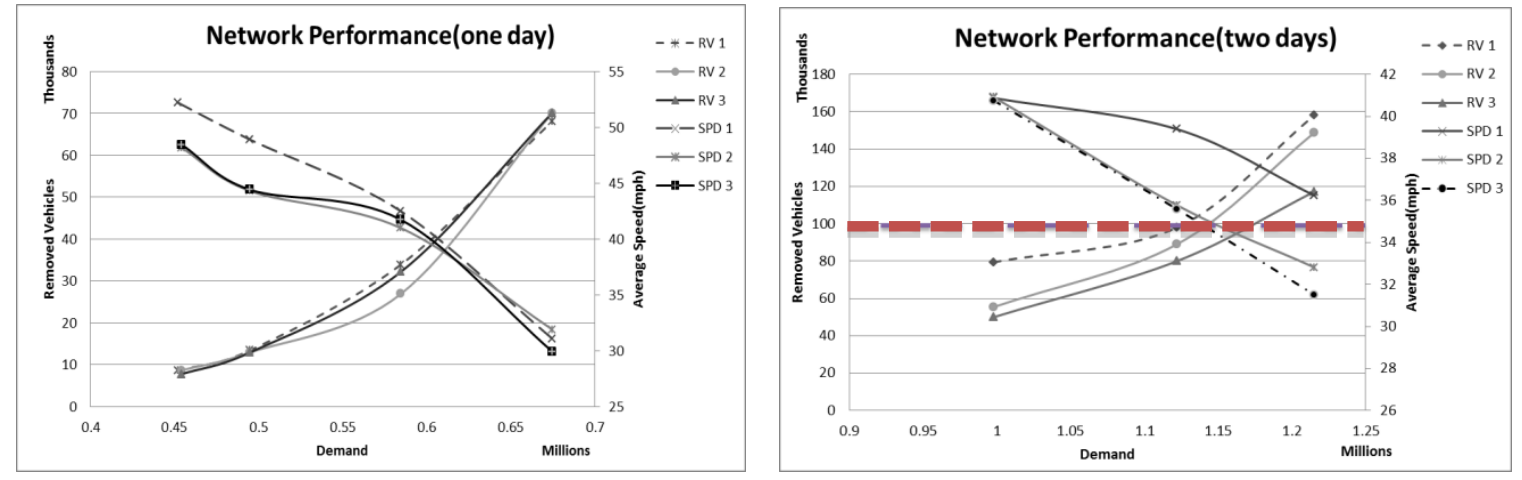

Figure 9. Network Performance Curves (Left side: two day evacuations; Right side: single day evacuations)

This work demonstrates advancement over existing practice and knowledge because it permits estimates of the number of vehicles removed and average travel speed to generally show effects of contraflow plan on increase network capacity and also the potential negative effect on the average travel speed due to bottlenecks creased by contraflow operation. Thus, researchers can use these techniques and measures to forecast the potential congestion level for the whole megaregion area. Currently, existing models are limited because they can only compute the congestion level on certain segments of corridors or within small areas and they are often time consuming to code and execute. Network performance models such as the one presented here may also be used to inform decision-making in ways or locations during evacuation planning. For example, can/should evacuation orders be issued for one or two movements, how long should contraflow operations be used, and what may be the range of evacuation capacity for one - and two-day evacuations.

In terms of what this work tells about evacuation in megaregions, it suggests that can they be done, however, there are also limitations. First it demonstrates some of the variation of network performance during megaregion evacuations. In this study, the removed vehicles would increase very slowly until the evacuation demand raised and below a certain critical value, then it deteriorated rapidly as the demand exceed this critical threshold value. The average travel speed performance measure followed a similar pattern; influenced by prevailing free flow speeds and travel demand. However, the effect of contraflow plans on removed vehicles and average travel speed differed as it markedly increased evacuation network capacity. However, the simulation results suggest that these gains were often achieved at the cost of creating bottlenecks at contraflow initiation and termination points. 
Limitation in network performance functions suggest that the contraflow parameter is closely determined by the network topology, contraflow plan location and duration time, would be difficult to estimate through means other than simulation. In the future it is theorized that more simulations on different megaregion networks could be used to investigate a more generalizable network performance function.

The work here can be useful on a practical level as well. It could be used for emergency managers to estimate the possible network performance in megaregion given reasonable estimated of evacuation demand from demand model like MNL and TDSLM. Although the network performance functions developed and described in this paper were specific to the Gulf Coast of the US, these methodologies can also be applied in other megaregions in the world.

\section{Acknowledgments}

The authors wish to acknowledge research support provided by the United States Department of Transportation's Research and Innovative Technology Administration's University Transportation Centers Program through their sponsorship of the Southwest University Transportation Center at Texas A\&M University and the Gulf Coast Center for Evacuation and Transportation Resiliency at Louisiana State University.

\section{References}

[1] J. Gottman, "Megalopolis: The Urbanized Northeastern Seaboard of the United States", New York: Twentieth Century Fund, (1961).

[2] Z. Zhang, K Spansel and B. Wolshon, "Megaregion Network Simulation for Evacuation Analysis", accepted for publication in the Transportation Research Record, (2013) February.

[3] R. Florida, "The Rise of the Mega Region", The Martin Prosperity Institute, University of Toronto, (2007).

[4] M. A. Bender, "Model impact of anthropogenic warming on the frequency of intense Atlantic hurricanes", Science, vol. 327, (2010), pp. 454-458.

[5] P. Toohey, "Mass Evacuations as Mega Storm Sandy Approaches the United States", Available: http://www.mnialive.com/global-connect/usa/3150-mass-evacuations-as-mega-storm-sandy-approaches-theunited-states.html [Accessed June 15, 2013], (2012), October.

[6] G. Theodoulou, "Contraflow Evacuation on the Westbound I-10 out of the City of New Orleans", Master Thesis, Louisiana State University, Baton Rouge, LA, (2003).

[7] E. Lim and B. Wolshon, "Modeling and Performance Assessment of Contraflow Evacuation Termination Points", Transportation Research Record 1922, (2005).

[8] B. M. Williams, A. P. Tagliaferri, S. S. Meinhold, J. E. Hummer and N. M. Rouphail, "Simulation and Analysis of Freeway Lane Reversal for Coastal Hurricane Evacuation", ASCE Journal of Urban Planning and Development, vol. 133, no. 1, (2007), pp. 61-72.

[9] V. V. Dixit, S. Ramasamy and A. E. Radwan, "Assessment of I-4 Contraflow Plans Microscopic vs. Mesoscopic Simulation”, Transportation Research Record Number 2041, (2008), pp. 89-97.

[10] M. Jha, K. Moore and B. Pashaie, "Emergency Evacuation Planning with Microscopic Traffic Simulation", Transportation Research Record 1886, (2004).

[11] H. Sbayti and H. S. Mahmassani, "Optimal Scheduling of Evacuation Operations", Transportation Research Record 1964, (2006), pp. 238-246.

[12] A. G. Hobeika and B. Jamei, "MASSVAC: A Model for Calculating Evacuation Times under Natural Disasters", Computer Simulation in Emergency Planning, La Jolla, Society of Computer Simulation, (1985).

[13] A. Kirschenbaum, "Warning and Evacuation During a Mass Disaster: A Multivariate Decision-Making Model", International journal of Mass Emergencies and Disasters, vol. 10, no. 1, (1992), pp. 91-114.

[14] KLD, "Formulations of the DYNEV and I-DYNEV Traffic Simulation Models Used in ESF", Federal Emergency Management Agency, (1984).

[15] Y. Chiu, H. Zheng, J. A. Villalobos, W. Peacock and R. Henk, "Evaluating Regional Contra-Flow and Phased Evacuation Strategies for Texas Using a Large-Scale Dynamic Traffic Simulation and Assignment Approach", Journal of Homeland Security and Emergency Management, vol. 5, no. 1, Article 34, (2008).

[16] V. V. Dixit, T. Montz and B. Wolshon, "Validation Techniques for Region-Level Microscopic Mass Evacuation Traffic Simulations”, Transportation Research Record, vol. 2229, (2011), pp. 66-74. 
[17] B. Wolshon, J. Lefante, H. Naghawi, T. Montz and V. Dixit. "Application of TRANSIMS for the Multimodal Microscale Simulation of the New Orleans Emergency Evacuation Plan”, Technical Report, (2009) July.

[18] G. Ravindra and C. G. Wilmot, "A Comparison of Time-Dependent Sequential Logit and Nested Logit for Modeling Hurricane Evacuation Demand”, Transportation Research Record: Journal of the Transportation Research Board, No. 3959, Transportation Research Board of the National Academies, Washington, D. C., (2012).

[19] T. Montz and Z. Zhang, "Calibration and Validation of a Regional-Level Traffic Model for Hurricane Evacuation", Submitted for Natural Hazards Review. 
International Journal of Transportation Vol.2, No.3 (2014) 